\title{
Childhood Hearing Impairment, Gender, and Trait Neuroticism as Independent Predictors of the Occurrence of Hearing Problems in Adulthood
}

\author{
Helen Cheng1,2, Adrian Furnham ${ }^{3 *}$ \\ ${ }^{1}$ Research Department of Clinical, Educational and Health Psychology, University College London, London, UK \\ ${ }^{2}$ ESRC Centre for Learning and Life Chances in Knowledge Economies and Societies, Institute of Education, \\ University College London, London, UK \\ ${ }^{3}$ Norwegian Business School, Oslo, Norway \\ Email: *a.furnham@ucl.ac.uk
}

How to cite this paper: Cheng, $H$. and Furnham, A. (2019) Childhood Hearing Impairment, Gender, and Trait Neuroticism as Independent Predictors of the Occurrence of Hearing Problems in Adulthood. Health, 11, 81-90.

https://doi.org/10.4236/health.2019.111009

Received: November 25, 2018

Accepted: January 27, 2019

Published: January 30, 2019

Copyright (C) 2019 by author(s) and Scientific Research Publishing Inc. This work is licensed under the Creative Commons Attribution International License (CC BY 4.0).

http://creativecommons.org/licenses/by/4.0/

\begin{abstract}
This study explored psychological, biomedical, and social factors in childhood and adulthood associated with the occurrence of self-reported hearing problems in adulthood. In total, 4828 participants with complete data on parental social class at birth, childhood hearing impairment measured at age 7 years and cognitive ability accessed at age 11 years, educational qualifications obtained at age 33 years, the Big-Five-Factor personality traits measured at age 50 years, current occupational levels and self-reported hearing problems at age 54 years were included in the study. Logistic regression analysis showed that among all the factors examined childhood hearing impairment and trait neuroticism as well as gender were the significant and independent predictors of hearing problems in adulthood.
\end{abstract}

\section{Keywords}

Hearing Problems in Childhood and Adulthood, Childhood Intelligence, Personality Traits, Longitudinal

\section{Introduction}

Although there is a literature in the psychological correlates of general health conditions [1] [2] [3] [4], few have looked at the specific associations between psychological factors and hearing problems in adulthood. This study sets out to 
explore the psychological, biomedical, and socio-demographic factors in childhood and adulthood associated with the occurrence of self-reported hearing problems in adulthood, using a large birth cohort in the UK.

Studies on personality and health have consistently implicated two traits: Conscientiousness and Neuroticism [3] [4]. Conscientious people are more planful, reliable and organised. They tend to take more responsibility for their own health and follow medical advice. Hence, they expose themselves less to health hazards and keep abreast of medical developments. Neurotics are prone to anxiety and depression and tend to have poor coping strategies which can adversely affect all chronic conditions. Further, they are more likely to report physical illness and discomfort which may primarily account for the association between Neuroticism and many illnesses. This makes it unclear as to whether Neuroticism is linked to actual illness or merely the reporting of illness. However, a key component of Neuroticism is somaticizing unhappiness and stress into a number of specific illnesses.

The possible association between personality and hearing problems may occur for various reasons. Personality traits may manifest themselves in a lifestyle that can adversely affect hearing. Equally early hearing loss could affect personality development. Early research questions concerned the "typical personality" of deaf children such as impulsivity, rigidity and suspiciousness [5]. Various studies have looked at the self-concept and self-esteem of deaf people [6], and found that deaf adolescents, as opposed to hearing adolescents, showed lower levels of self-perceived social acceptance, close friendships and ego development. In a similar study done in Ethiopia [7], the authors noted deaf students had a lower general, school and reading self-confidence as well as poorer parental relations.

Another study [8] found that deaf adults reported lower self-esteem than their hearing peers, and that self-esteem contributed to adult functioning such as differentiation from original family and ability for spousal intimacy. Previous study [9] also found various sub-clinical mental illnesses associated with deafness including hypochondriasis, paranoia and schizophrenia.

One study [10] established that children with hearing loss wearing cochlear implants or hearing aids rated global self-esteem more positively than their hearing peers. Further, higher self-esteem scores are related to higher affiliation and attention domains, as well as lower scores in depressive mood domain. These findings are in line with some published reports [11] [12] but contradict others finding less positive self-esteem in children with hearing loss [13] [14] [15] [16] or no differences based on hearing status [17] [18] [19].

As well as personality a number of studies demonstrated the link between intelligence and health outcomes, for example, between childhood intelligence and type 2 diabetes [20], and between childhood intelligence and mortality [21]. Previous studies have established the links between socioeconomic conditions and health [22] [23]. In this study we will also examine the relationship between intelligence, education, social class and hearing problems. 


\section{Hypotheses}

The current study explored psychological, biomedical and socio-demographic factors in childhood and adulthood associated with the occurrence of self-reported hearing problems in adulthood. The present study has two strengths compared with many previous studies in the area. First, it used a large prospective birth cohort. Second, it looks at two main aspects of individual differences (personality and intelligence) and their associations with hearing problems. Based on the previous findings, it is hypothesised that higher socioeconomic background with better education, more intelligent, emotionally more stable (i.e. non neurotic) and more conscientious individuals would report less hearing problems in adulthood.

\section{Method}

\subsection{Sample}

The National Child Development Study 1958 is a large-scale longitudinal study of the 17,415 individuals who were born in Great Britain in a week in March 1958 [24]. The following analysis is based on data collected when the study participants were at birth, at ages $7,11,33,50$, and 54 years. The analytic sample comprises 4828 cohort members (50.1 per cent females) with complete data. Analysis of response bias in the cohort data showed that the achieved adult samples did not differ from their target sample across a number of critical variables (social class, parental education and gender), despite a slight under-representation of the most disadvantaged groups [25].

\subsection{Measures}

Childhood measures: Parental social class at birth was measured by the Registrar General's measure of social class (RGSC). RGSC is defined according to occupational status and the associated education, prestige or lifestyle [26] and is assessed by the current or last held job. Where the father was absent, the social class (RGSC) of the mother was used. RGSC was coded on a six-point scale from unskilled to professional occupations [27]. At birth, mothers were interviewed and provided information on gestational age and birth weight. Mothers also provided information on whether participants ever had hearing impairment by the age of 7 years diagnosed by physicians. Childhood cognitive ability tests [28] were accessed when cohort members were at age 11 years consisting of 40 verbal and 40 non-verbal items and were administered at school.

Adulthood measures: At age 33, participants were asked about their highest academic or vocational qualifications. Responses are coded to the six-point scale of National Vocational Qualifications levels (NVQ) which ranges from "none" to "university degree/higher"/equivalent NVQ 5 or 6 . Personality traits were assessed by the 50 questions from the International Personality Item Pool (IPIP) [29]. Responses (5-point, from "Strongly Agree" to "Strongly Disagree") are summed to provide scores on the "Big-Five" personality traits: Extraversion, Emo- 
tionality/Neuroticism, Conscientiousness, Agreeableness, and Intellect/Openness. $\mathrm{Z}$ scores were used for the analyses. At age 54 participants provided information on their current or last occupation levels coded according to the Registrar General's Classification of Occupations (RGSC), using a 6-point described mentioned above, and whether they were having hearing problems (partial or total hearing loss in one ear or both ears/repeated ear infections/discharge/tinnitus/ Meniere's Disease/other hearing problem) with Yes/No response.

\subsection{Statistical Analyses}

To investigate the psychological, biomedical, and socio-demographic factors associated with the occurrence of self-reported hearing problems in adulthood, we first examined the characteristics of the study population. Second, correlation matrix of all the variables used in the study was examined. Third, we carried out the logistic regression analysis using STATA version 14 using self-reported hearing problems in adulthood as the dependent variable.

\section{Results}

\subsection{Descriptive Analysis}

Table 1 shows the characteristics of the study population according to the occurrence of hearing problems at 54 years. First, it appeared that cohort members who had professional or managerial family background and had highest educational qualification (university degree) with current professional occupation tended to report less hearing problems. There were also sex differences: men reported more than women on hearing problems (12.7\% and $7.9 \%$ respectively). The chi-square test showed that these differences were statistically significant $\left(\chi^{2}\right.$ $(1, \mathrm{~N}=4828)=29.93, p<0.001)$.

\subsection{Correlational Analysis}

Table 2 shows the results of correlational analysis. Participants who had hearing impairment in childhood were more likely to have hearing problems in adulthood. Parental social class, current occupational levels, personality traits Emotional Stability (low Neuroticism) and Conscientiousness as well as gender were all statistically significantly associated with the occurrence of hearing problems in adulthood $(p<0.05$ to $p<0.001)$.

\subsection{Regression Analysis}

Table 3 shows the results of logistic regression using self-reported hearing problems in adulthood as the dependent variable. The model shows that among all psychological, biomedical and socio-demographic factors in childhood and adulthood examined, gender, childhood hearing impairment, and trait Neuroticism were the only significant and independent predictors of the outcome variable. That is, of all five personality traits examined it was only trait Neuroticism that predicted hearing problems in adulthood. 
Table 1. Social and demographic characteristics of the study population and occurrence of hearing problems at age 54 years.

\begin{tabular}{|c|c|c|c|}
\hline & $\mathrm{n}$ & $\%$ & Occurrence of hearing problems $\%$ \\
\hline \multicolumn{4}{|l|}{ Gender } \\
\hline Male & 2412 & 49.9 & 12.7 \\
\hline Female & 2416 & 50.1 & 7.9 \\
\hline \multicolumn{4}{|l|}{ Parental social class at birth } \\
\hline Unskilled (V) & 334 & 6.9 & 9.3 \\
\hline Partly skilled (IV) & 563 & 11.7 & 13.3 \\
\hline Skilled manual (III) & 2335 & 48.4 & 10.7 \\
\hline Skilled non-manual (III) & 534 & 11.1 & 9.7 \\
\hline Managerialıtech (II) & 778 & 16.1 & 8.5 \\
\hline Professional (I) & 284 & 5.9 & 8.1 \\
\hline \multicolumn{4}{|l|}{ Educational qualifications } \\
\hline No qualifications & 313 & 6.5 & 13.8 \\
\hline CSE 2-5/equivalent NVQ1 & 550 & 11.4 & 10.7 \\
\hline O Level/equivalent NVQ2 & 1681 & 34.8 & 9.2 \\
\hline A level/equivalent NVQ3 & 739 & 15.3 & 13.0 \\
\hline Higher qualification/equivalent NVQ4 & 779 & 16.1 & 9.4 \\
\hline University Degree/equivalent NVQ5, 6 & 766 & 15.9 & 9.3 \\
\hline \multicolumn{4}{|l|}{ Current social class } \\
\hline Unskilled (V) & 93 & 1.9 & 9.7 \\
\hline Partly skilled (IV) & 549 & 11.4 & 12.4 \\
\hline Skilled manual (III) & 839 & 17.4 & 12.9 \\
\hline Skilled non-manual (III) & 984 & 20.4 & 8.5 \\
\hline Managerial ltech (II) & 2027 & 42.0 & 9.7 \\
\hline Professional (I) & 336 & 7.0 & 7.0 \\
\hline
\end{tabular}

Table 2. Pearson product-moment correlations of variables in the study.

\begin{tabular}{|c|c|c|c|c|c|c|c|c|c|c|c|c|c|c|}
\hline & Variables & $\begin{array}{l}\text { Mean } \\
\text { (SD) }\end{array}$ & 1 & 2 & 3 & 4 & 5 & 6 & 7 & 8 & 9 & 10 & 11 & 12 \\
\hline 1) & Gender & $\begin{array}{c}0.50 \\
(0.50)\end{array}$ & - & & & & & & & & & & & \\
\hline 2) & $\begin{array}{l}\text { Hearing problems } \\
\text { at age } 54\end{array}$ & $\begin{array}{c}0.10 \\
(0.30)\end{array}$ & $-0.079^{* * *}$ & - & & & & & & & & & & \\
\hline 3) & $\begin{array}{c}\text { Hearing } \\
\text { impairment } \\
\text { at age } 7\end{array}$ & $\begin{array}{c}0.11 \\
(0.32)\end{array}$ & -0.029 & $0.103^{* * *}$ & - & & & & & & & & & \\
\hline 4) & $\begin{array}{l}\text { Parental social } \\
\text { class at birth }\end{array}$ & $\begin{array}{c}3.35 \\
(1.25)\end{array}$ & -0.024 & $-0.033^{*}$ & -0.029 & - & & & & & & & & \\
\hline 5) & $\begin{array}{l}\text { Childhood } \\
\text { intelligence }\end{array}$ & $\begin{array}{c}104.3 \\
(12.69)\end{array}$ & $0.067^{\star * *}$ & $-0.054^{* * *}$ & 0.021 & $0.268^{\star * *}$ & - & & & & & & & \\
\hline 6) & $\begin{array}{c}\text { Educational } \\
\text { qualifications }\end{array}$ & $\begin{array}{c}2.71 \\
(1.45)\end{array}$ & $-0.086^{* * *}$ & -0.020 & -0.011 & $0.341^{\star \star \star}$ & $0.482^{* * *}$ & - & & & & & & \\
\hline
\end{tabular}




\section{Continued}

\begin{tabular}{|c|c|c|c|c|c|c|c|c|c|c|c|c|c|}
\hline 7) & $\begin{array}{c}\text { Current } \\
\text { occupational levels }\end{array}$ & $\begin{array}{c}4.10 \\
(1.22)\end{array}$ & 0.005 & $-0.034^{*}$ & 0.007 & $0.227^{\star * *}$ & $0.332^{\star * *}$ & $0.450^{\star * \star}$ & - & & & & \\
\hline 8) & Extraversion & $\begin{array}{l}29.44 \\
(6.62)\end{array}$ & $0.072^{* * *}$ & -0.026 & -0.014 & $0.033^{*}$ & 0.025 & $0.074^{\star * *}$ & $0.139^{\star * *}$ & - & & & \\
\hline 9) & $\begin{array}{l}\text { Emotional } \\
\text { stability }\end{array}$ & $\begin{array}{l}29.11 \\
(7.04)\end{array}$ & $-0.144^{\star * *}$ & $-0.051^{* * *}$ & 0.017 & 0.029 & $0.079^{\star * *}$ & $0.086^{* * *}$ & $0.070^{\star * *}$ & $0.224^{\star * *}$ & - & & \\
\hline 10) & Agreeableness & $\begin{array}{l}36.82 \\
(5.24)\end{array}$ & $0.400^{* * *}$ & 0.027 & -0.001 & $0.037^{*}$ & $0.107^{\star * *}$ & $0.066^{* * *}$ & $0.118^{\star * *}$ & $0.360^{\star * *}$ & $0.057^{\star * *}$ & - & \\
\hline 11) & Conscientiousness & $\begin{array}{l}34.06 \\
(5.18)\end{array}$ & $0.099^{* * *}$ & $-0.037^{\star}$ & -0.001 & -0.001 & 0.021 & $0.049^{* *}$ & $0.079^{\star * *}$ & $0.146^{\star * *}$ & $0.176^{\star * *}$ & $0.266^{\star * *}$ & - \\
\hline 12) & Openness & $\begin{array}{l}32.59 \\
(5.18)\end{array}$ & -0.030 & -0.024 & 0.003 & $0.137^{\star * *}$ & $0.264^{\star * *}$ & $0.314^{* * *}$ & $0.249^{\star * *}$ & $0.401^{\star * *}$ & $0.109^{\star * *}$ & $0.327^{\star * *}$ & $0.218^{* * *}$ \\
\hline
\end{tabular}

Note: ${ }^{\star} p<0.05 ;{ }^{* *} p<0.01 ;{ }^{* *} p<0.001$. Variables were scored such that a higher score indicated being female, the presence of hearing problems in childhood or adulthood, a more professional occupation for parents or cohort members, higher scores on childhood intelligence, highest educational qualification, higher scores on traits extraversion, emotional stability, agreeableness, conscientiousness, and openness. Associations between hearing problems in adulthood and other variables are in bold.

Table 3. Odds ratios (95\% CI) for hearing problems at age 54, according to parental social class, gender, hearing impairment and intelligence in childhood, education and occupation, and personality traits.

\begin{tabular}{|c|c|c|}
\hline Measures & Odds ratio $(95 \% \mathrm{CI})$ & $p$-value \\
\hline Gender & $0.53(0.41,0.70)^{\star \star \star}$ & $<0.000$ \\
\hline \multicolumn{3}{|c|}{ Parental social class at birth (unskilled as reference group) } \\
\hline Partly skilled & $1.43(0.84,2.44)$ & 0.186 \\
\hline Skilled manual & $1.00(0.62,1.61)$ & 0.995 \\
\hline Skilled non-manual & $1.01(0.58,1.77)$ & 0.958 \\
\hline Managerial $\mid t e c h$ & $0.85(0.49,1.47)$ & 0.564 \\
\hline Professional & $0.78(0.39,1.56)$ & 0.480 \\
\hline Childhood hearing impairment & $2.23(1.98,2.97)^{\star * *}$ & $<0.001$ \\
\hline Childhood intelligence & $0.95(0.82,1.10)$ & 0.510 \\
\hline \multicolumn{3}{|c|}{ Educational qualifications (no qualification as reference group) } \\
\hline CSE 2-5/equivalent NVQ1 & $0.70(0.40,1.24)$ & 0.219 \\
\hline O Level/equivalent NVQ2 & $0.90(0.55,1.46)$ & 0.663 \\
\hline A level/equivalent NVQ3 & $1.30(0.77,2.19)$ & 0.328 \\
\hline Higher qualification/equivalent NVQ4 & $0.98(0.56,1.68)$ & 0.918 \\
\hline University Degree/equivalent NVQ5, 6 & $1.00(0.55,1.81)$ & 0.996 \\
\hline \multicolumn{3}{|l|}{ Current social class (unskilled as reference group) } \\
\hline Partly skilled & $1.17(0.52,2.65)$ & 0.703 \\
\hline Skilled manual & $0.84(0.38,1.87)$ & 0.673 \\
\hline Skilled non-manual & $0.80(0.36,1.80)$ & 0.592 \\
\hline Managerial/tech & $0.81(0.37,1.79)$ & 0.602 \\
\hline Professional & $0.68(0.27,1.70)$ & 0.407 \\
\hline Extraversion & $0.99(0.87,1.12)$ & 0.827 \\
\hline Emotional stability & $0.79(0.70,0.89)^{\star \star \star}$ & $<0.001$ \\
\hline Agreeableness & $1.04(0.91,1.19)$ & 0.529 \\
\hline Conscientiousness & $0.94(0.83,1.06)$ & 0.286 \\
\hline Openness & $0.98(0.85,1.12)$ & 0.729 \\
\hline
\end{tabular}

Note: ${ }^{* *} p<0.001$. Adjusted for gestational age and birth weight. 


\section{Discussion}

The present study set out to explore the associations between psychological, biomedical and socio-demographic factors and hearing problems in adulthood. This study is among the first to look at associations between the two main components of individual differences (intelligence and personality) and hearing problems. We searched the literature and found that while there were many studies on personality (and other) correlates of various physical complaints there were relatively few studies of hearing difficulties. Nevertheless, those studies have often identified trait Neuroticism as a correlate of any disorder, illness or physical complaint [30] [31] [32].

The correlational results suggested seven variables were related to hearing problems in adulthood. The strongest correlate was hearing problems at age 7 yrs suggesting that these problems were stable over time due to physical damage. Adults with hearing problems were also more likely to come from lower social class families and achieve a lower occupational level themselves. Clearly hearing problems can lead to educational difficulties and under-achievement, which in turn, leads to fewer occupational opportunities.

The findings showed that hearing impaired people also tended to be less intelligent, more neurotic and less conscientious. However, the binary regressions highlighted just three factors: early hearing problems, gender and Neuroticism.

The correlational results are particularly interesting because they show non-significant correlations between hearing problems at aged 7 and various other measures like intelligence measured at age 11 (4 years later) or personality measured at aged 50 (43 years later). This suggests that early hearing impairment does not have a big impact on personality functioning or intellectual development, but rather the other way around. This is important as it could be argued that early childhood hearing impairment could have a major impact on the development of all personality traits. For instance, because social interaction is more difficult, hearing impaired children are less likely to become confident extraverts. Similarly, they may have greater restrictions on various forms of exploration, so reducing their Openness to Experience.

Previous studies found the link between intelligence and a number of health conditions such as diabetes [20] and mortality [21], the current study shows that intelligence measured in childhood is also significantly associated with hearing problems in adulthood. However, this association has ceased to be significant once personality and other socio-demographic factors are taken into account.

Among the five personality factors, traits Conscientiousness and Neuroticism are bound to be linked with a number of health conditions [3]. The current study shows that these two traits are also associated with hearing problems, and Emotional Stability is the only significant predictor of the outcome variable. Nearly all studies in this area have suggested a relationship between some measure of low adjustment and poor coping and hearing impairment which makes perfect sense given the social difficulties and disadvantages associated with this condition. This may change with the introduction of new physiological tech- 
niques to deal with hearing impairment, as well as a change in the general publics' attitude to those with hearing difficulties.

Among social factors, although parental social class, education and occupation are significantly associated with hearing problems in adulthood, they are not significant predictors of the outcome variable. Results show that as expected, childhood hearing impairment may have a substantial effect on individuals" lives 47 years later. Those who had hearing impairment in childhood are more than twice likely to have the same health conditions in adulthood. This may imply an etiological base of this health condition.

The reason of gender effect on hearing problems in adulthood is unclear. It appears more puzzling that such effect does not occur in childhood diagnosed by physicians. This may be the result of women over-reporting problems compared to men and needs further investigation. This finding confirms many other studies in the literature mentioned above and suggests the need for people with hearing disorders to be given advice and therapy to cope better with the social problems that may arise from their hearing conditions.

The present study is based on available variables in the dataset rather than being based on the study designed for the purpose, which we might like to have included. Further, in this study the outcome variable is rather general without specific medically defined terms, about the type, or severity of the hearing problem. Also personality traits were measured only once. Only with repetitive measures accessed periodically can the mechanisms and processes of these associations be better understood. Therefore, future studies should be conducted to confirm or refute the expected and unexpected findings in the present study. Nevertheless this study did highlight the importance of studying personality factors in hearing disorders.

\section{Conclusion}

In conclusion, this study showed there were few demographic or personality trait predictors of adult hearing problems. Indeed, the only correlate in our data was trait Neuroticism, or low Emotional Stability which inevitably might have been affected by a lifetime of communication difficulties associated with hearing impairment of many kinds.

\section{Acknowledgements}

Data from the Cohort Studies were supplied by the ESRC Data Archive. Those who carried out the original collection of the data bear no responsibility for its further analysis and interpretation.

\section{Conflicts of Interest}

The authors declare no conflict of interest.

\section{References}

[1] Atherton, O.E., Robins, R.W., Rentfrow, P.J. and Lamb, M.E. (2014) Personality 
Correlates of Risky Health Outcomes: Findings from a Large Internet Study. Journal of Research in Personality, 50, 56-60. https://doi.org/10.1016/j.jrp.2014.03.002

[2] Chapman, B.P., Roberts, B.W. and Duberstein, P. (2011) Personality and Longevity: Knowns, Unknowns, and Implications for Public Health and Personalized Medicine. Journal of Aging Research, 2011, Article ID: 759170.

https://doi.org/10.4061/2011/759170

[3] Friedman, H. and Kern, M. (2014) Personality, Well-Being and Health. Annual Review of Psychology, 65, 719-742.

https://doi.org/10.1146/annurev-psych-010213-115123

[4] Matthews, G., Deary, I. and Whiteman, M. (2009) Personality Traits. Cambridge University Press, Cambridge. https://doi.org/10.1017/CBO9780511812743

[5] Chess, S. and Fernandez, P. (1980) Do Deaf Children Have a Typical Personality? Journal of the American Academy of Child Psychiatry, 19, 654-664.

https://doi.org/10.1016/S0002-7138(09)60968-7

[6] Van Gent, T., Goedhart, A., Knoors, H., Westerbrg, P. and Treffers, P. (2012) Self-Concept and Ego Development in Deaf Adolescents. Journal of Deaf Studies and Deaf Education, 17, 333-352. https://doi.org/10.1093/deafed/ens002

[7] Mekonnen, M., Hannu, S., Elina, L. and Matti, K. (2016) The Self-Concept of Deaf/Hard-of-Hearing and Hearing Students. Journal of Deaf Studies, 21, 345-351. https://doi.org/10.1093/deafed/enw041

[8] Levinger, M. and Ronen, T. (2010) The Link among Self-Esteem, Differentiation, and Spousal Intimacy in Deaf and Hearing Adults. Journal of Social Work in Disability \& Rehabilitation, 9, 27-52. https://doi.org/10.1080/15367100903526120

[9] Sanchez, G., Sanchez, D., Ramon, L. and del Canizo, F.-R. (2000) Personality Study in Profoundly Deaf Adults. Revue de Laryngologie Otologie Rhinologie, 12, 339-343.

[10] Warner-Czyz, A.D., Loy, B.A., Evans, C., Wetsel, A. and Tobey, E.A. (2015) Self-Esteem in Children and Adolescents with Hearing Loss. Trends in Hearing, 19, 1-12. https://doi.org/10.1177/2331216515572615

[11] Koelle, W.H. and Convey, J.J. (1982) The Prediction of the Achievement of Deaf Adolescents from Self-Concept and Locus of Control Measures. American Annals of the Deaf, 127, 769-779. https://doi.org/10.1353/aad.2012.1374

[12] Cates, J. (1991) Self-Concept in Hearing and Prelingual, Profoundly Deaf Students. American Annals of the Deaf, 136, 352-359. https://doi.org/10.1353/aad.2012.0499

[13] Bat-Chava, Y. and Deignan, E. (2001) Peer Relationships of Children with Cochlear Implants. Journal of Deaf Studies and Deaf Education, 6, 186-199. https://doi.org/10.1093/deafed/6.3.186

[14] Huber, M. (2005) Health-Related Quality of Life of Austrian Children and Adolescents with Cochlear Implants. International Journal of Pediatric Otorhinoloaryngology, 69, 1089-1101. https://doi.org/10.1016/j.ijporl.2005.02.018

[15] Tambs, K. (2004) Moderate Effects of Hearing Loss on Mental Health and Subjective Well-Being: Results from the Nord-Trøndelag Hearing Loss Study. Psychosomatic Medicine, 66, 776-782. https://doi.org/10.1097/01.psy.0000133328.03596.fb

[16] Weisel, A. and Kamara, A. (2005) Attachment and Individuation of Deaf/Hard-ofHearing and Hearing Young Adults. Journal of Deaf Studies and Deaf Education, 10, 51-62. https://doi.org/10.1093/deafed/eni003

[17] Kluwin, T. (1999) Co-Teaching Deaf and Hearing Students: Research on Social In- 
tegration. American Annals of the Deaf, 144, 339-344.

https://doi.org/10.1353/aad.2012.0337

[18] Sahli, S., Arslan, U. and Belgin, E. (2009) Depressive Emotioning in Adolescents with Cochlear Implant and Normal Hearing. International Journal of Paediatric Otorhinoloaryngology, 73, 1774-1779. https://doi.org/10.1016/j.ijporl.2009.09.027

[19] Sahli, S. and Belgin, E. (2006) Comparison of Self-Esteem Level of Adolescents with Cochlear Implant and Normal Hearing. International Journal of Paediatric Otorhinolaryngology, 70, 1601-1608. https://doi.org/10.1016/j.ijporl.2006.05.003

[20] Olsson, G.M., Hultin, A.L. and Montgomery, S.M. (2008) Cognitive Function in Children and Subsequent Type 2 Diabetes. Diabetes Care, 31, 514-516. https://doi.org/10.2337/dc07-1399

[21] Batty, G.D., Wennerstad, K.M., Smith, G.D., Gunnell, D., Deary, I.J., Tynelius, P. and Rasmussen, F. (2009) IQ in Early Adulthood and Mortality by Middle Age: Cohort Study of 1 Million Swedish Men. Epidemiology, 20, 100-109. https://doi.org/10.1097/EDE.0b013e31818ba076

[22] Marmot, M. (2007) Achieving Health Equity: From Root Causes to Fair Outcomes. The Lancet, 370, 1153-1163. https://doi.org/10.1016/S0140-6736(07)61385-3

[23] Wilkinson, R.G. and Pickett, K.E. (2006) Income Inequality and Population Health: A Review and Explanation of the Evidence. Social Science and Medicine, 62, 1768-1784. https://doi.org/10.1016/j.socscimed.2005.08.036

[24] Ferri, E., Bynner, J. and Wadsworth, M. (2003) Changing Britain, Changing Lives: Three Generations at the Turn of the Century. Institute of Education, London.

[25] Plewis, I., Calderwood, L., Hawkes, D. and Nathan, G. (2004) National Child Development Study and 1970 British Cohort Study, Technical Report: Changes in the NCDS and BCS70 Populations and Samples over Time. Institute of Education, Centre for Longitudinal Studies, London.

[26] Marsh, C. (1986) Social Class and Occupation. In: Burgess, R., Ed., Key Variables in Social Investigation, Routledge, London, 123-152.

[27] Leete, R. and Fox, J. (1977) Registrar General's Social Classes: Origins and Users. Population Trends, 8, 1-7.

[28] Douglas, J.W.B. (1964) The Home and the School. Panther Books, London.

[29] Goldberg, L.R. (1999) A Broad-Bandwidth, Public Domain, Personality Inventory Measuring the Lower-Level Facets of Several Five-Factor Models. Personality Psychology in Europe, 7, 7-28.

[30] Cheng, H., Deighton, J., Wolpert, M., Chapman, B., Kornilaki, K., Treglown, L. and Furnham, A. (2016) Hay Fever in Childhood, Traits Neuroticism and Conscientiousness as Predictors of the Occurrence of Hay Fever in Adulthood. Journal of Health Psychology, 21, 2367-2375. https://doi.org/10.1177/1359105315576784

[31] Cheng, H., Treglown, L., Montgomery, S., Kornilaki, E., Tsivrikos, D. and Furnham, A. (2017) The Associations between Personality Traits, Education, Occupation, and the Occurrence of Eczema in Adulthood: Evidence from a British Cohort. Journal of Health Psychology, 22, 916-924. https://doi.org/10.1177/1359105315618457

[32] Cheng, H., Montgomery, S., Treglown, L. and Furnham, A. (2017) Traits Emotional Stability and Conscientiousness, Sex, and Educational Qualifications Associated with Hypertension in Adulthood. Personality and Individual Differences, 115, 159-163. https://doi.org/10.1016/j.paid.2016.02.034 